\title{
Influence of feed delivery frequency on behavioural activity of dairy cows in freestall barns
}

\author{
Elisabetta Riva, Gabriele Mattachini, Luciana Bava, Anna Sandrucci, Alberto Tamburini, \\ Giorgio Provolo
}

Department of Agricultural and Environmental Science, University of Milan, Italy

\begin{abstract}
Research on feeding management in more competitive free-stall settings indicates that frequency of delivery of fresh feed stimulates feed bunk attendance and can affect other aspects of cows' time budgets apart from feeding such as time spent standing vs. lying down. The objective of this study was to examine how the frequency of feed delivery affects the behavior in two farms, one with a conventional and one with automatic milking system (AMS). The feeding frequency was varied from two to three times per day in the conventional dairy farm; one to two times per day in the AMS farm. The experiment was carried out in two different seasons. All behaviours of the cows were monitored in continuous by video recording. As expected, behavioral indices have been significantly affected by environmental conditions both in conventional farm and AMS farm. The variation in the frequency of feed delivery seems to affect the cow behavioural activity only in a limited way and modify only slightly the daily averages of the time spent in different activities mainly increasing the time cows spend standing (+4$5 \%)$.
\end{abstract}

\section{Introduction}

During the past few years, there has been increased interest in determining the effects that feeding frequency has on the perform-

Correspondence: Giorgio Provolo, Department of Agricultural and Environmental Science, University of Milan, via Celoria 2, 20133 Milano Italy. Tel.+39 0250316855 .

E-mail: giorgio.provolo@unimi.it

Key words: dairy cows; behaviour; environmental condition, automatic milking system.

Acknowledgements: this research was financially supported by the Ministry of University and Research (Italy) within the PRIN 2007 project on Innovative technical solutions for improving the production efficiency and the animal welfare in dairy cow housing.

(C) Copyright E. Riva et al., 2013

Licensee PAGEPress, Italy

Journal of Agricultural Engineering 2013; XLIV(s2):e39

doi:10.4081/jae.2013.s2.e39

This article is distributed under the terms of the Creative Commons Attribution Noncommercial License (by-nc 3.0) which permits any noncommercial use, distribution, and reproduction in any medium, provided the original author(s) and source are credited. ance of lactating dairy cows. Feeding is normally the predominant behavior in dairy cattle (Grant and Albright, 2001). Dairy cows spend 3 to $5 \mathrm{~h} / \mathrm{d}$ eating, consuming 9 to 14 meals per day. In addition, they ruminate 7 to $10 \mathrm{~h} / \mathrm{d}$, spend approximately $30 \mathrm{~min} / \mathrm{d}$ drinking, 2 to $3 \mathrm{~h} / \mathrm{d}$ being milked, and require approximately $10 \mathrm{~h} / \mathrm{d}$ of lying and (or) resting time (Grant and Albright, 2000). Typically, group-housed dairy cows are provided with fresh feed twice per day $(2 \times)$, or only once per day $(1 \times)$ to reduce labor costs. Research on feeding management in more competitive free-stall settings indicates that frequency of delivery of fresh feed stimulates feed bunk attendance (DeVries et al., 2003) and can affect other aspects of cows' time budgets apart from feeding such as time spent standing or ruminating while standing vs. lying down (Phillips and Rind, 2001). DeVries and von Keyserlingk (2005) showed that the time of provision of fresh feed strongly influenced the feeding behavior of dairy cows, these authors also found that the time of feed delivery affected lying behavior. DeVries et al. (2005) showed that increasing the frequency of feed delivery allowed the cows to increase their daily feeding time and increase the distribution of feeding time over the course of the day, improving access to fresh feed for all cows and to reduce sorting. Mäntysaari et al. (2006) compared cows fed a total mixed ration (TMR) once or 5 times a day and also found total eating time was longer when feed was delivered more often, but, cows fed 5 times a day increased restlessness and decreased lying time than cows fed once times a day. Haley et al. (2000) showed that individually housed cows in tie stalls tended to eat the majority of their feed during the day, and peak feeding activity occurred immediately following milking and feed distribution. Similar responses to milking and feeding have also been demonstrated for cows in free-stall housing (Tanida et al., 1984; DeVries et al., 2003; Wagner-Storch and Palmer, 2003). Heat stress, particularly temperature-humidity index (THI), reduce dry matter intake (DMI) and milk yield in lactating cows (West, 2003; West et al., 2003) and were also found to influence the dairy cows' time budget (Cook et al., 2007).

The effect of feeding frequency on the performance of dairy cows has been examined in many studies. Time spent feeding has also been shown to be correlated with milk production (Shabi et al., 2005). Gibson (1984) concluded that increasing the feeding frequency of dairy cows increased the milk fat percentage by an average of $7.3 \%$ and increased milk production by $2.7 \%$. In the studies by Shabi et al. (1999), Le Liboux and Peyraud (1999), and Kudrna et al. (2001), increasing feeding frequency increased the DMI of the TMR, but had no effect on milk production. Contrary to these results, in the study by Phillips and Rind (2001), the DMI and milk yield were higher with feeding once a day compared with 4 times a day and concluded that frequent feeding disturbed the cows and reduced milk production.

Conventional milking systems provide a more structured daily routine, whereas automatic milking systems (AMS) allow for more flexibility in milking times for individual cows (Wagner-Storch and Palmer, 2003). According to Melin et al. (2005) the motivation to eat is a better incentive in attracting the cows to the milking unit than the motivation to be milked (Prescott et al., 1998; Halachmi et al., 2000). Oostra 
et al. (2005) reported that the daily number of visits to the AMS was not affected by the feeding frequency, however, an increase of frequency had a positive effect on the utilization of the cowshed facilities, such as the occupation of the feeding fence, cubicles, and feed alley. The daily feeding time is also influenced by the cow traffic system (Hermans et al., 2003).

The objective of this study was to examine how the frequency of feed delivery affects the time budget, considering also feed intake and milk production, in lactating dairy cows in conventional and AMS farms.

\section{Materials and Methods}

\section{Housing system and animals}

The study was carried out between April and November 2009 in two dairy farms located in Lombardy (Italy) where animals were kept in loose housing condition with cubicles.

In the first farm (conventional) animals were milked in a herringbone milking parlour $(12+12)$ twice daily and were divided in two groups (primiparous and pluriparous). Milking occurred twice a day at 05:00 and 17:00 h. The barn is oriented NW-SE, the studied a group of 96 primiparous was housed in the NE side equipped with 100 cubicles ( 2 rows) with mattress covered with chopped straw. At the beginning of the data collection period, cows were $214 \pm 9.37$ (mean \pm SD) days in milking (DIM) and the average milk yield was $27.1 \pm 0.66 \mathrm{~kg} / \mathrm{d}$. The manger has 90 feeding space and there are 8 fans for summer ventilation. The layout of the barn is reported in Figure 1. Cows were fed with total mixed ratio (22 kg of dry matter head ${ }^{-1}$ ).

In the second farm cows were milked in two AMS (VMS, DeLaval, Tumba, Sweden). A forced traffic was applied so the animals were forced to pass through the AMS before they could reach the feed troughs. Cows were divided in two pens but all animals had access to the both AMS $24 \mathrm{~h} / \mathrm{d}$ (while a total of $0.5 \mathrm{~h} / \mathrm{d}$ was dedicated to the cleaning of the system from 5.30 to 6 a.m.). Cows were granted milking permission after $6 \mathrm{~h}$ from previous milking, unless a milking failure occurred, in which case cows would be allowed permission to be milked again immediately. Cows with more than $12 \mathrm{~h}$ since last milking were fetched and forced to visit AMS.

The barn is oriented E-W, the studied a group of around 50 primiparous and multiparous cows (parity $1.83 \pm 0.03$, milk yield $30.0 \pm 3.05$ $\mathrm{kg} / \mathrm{d}$, DIM $193 \pm 17.8$; mean \pm SD) was housed in the $\mathrm{N}$ side equipped with 61 cubicles ( 4 rows) with mattress covered with sawdust. The manger has 39 feeding space and there are 2 fans for summer ventilation. The layout of the barn is reported in Figure 1. Cows were fed with total mixed ratio (19.8 $\mathrm{kg}$ of dry matter head $\left.{ }^{-1}\right)$.

\section{Environmental monitoring}

Two data loggers, for each farm, were used for the measurement of the air temperature, relative humidity and light intensity (HOBO U12 Temp/RH/Light/External Data Logger, Onset Computer Corporation, Bourne, MA, USA). The data loggers were located in the barn at a height of about $2 \mathrm{~m}$ above the floor in order to measure the air temperature as close as possible to the animals without being affected by the animals. The microclimatic data interval time recording was set at 15 min. The temperature-humidity index (THI), which is widely utilized in literature, was used to consider the temperature and the humidity jointly. The THI was calculated for each position in the barn and an overall value for the THI was obtained by averaging the data obtained from each data logger. The equation used to calculate THI was: $\mathrm{THI}=$ $\mathrm{Tdb}+0.36 \times \mathrm{Tdp}+41.2$, where $\mathrm{Tdb}$ is the dry bulb temperature in ${ }^{\circ} \mathrm{C}$, and Tdp is the dew point temperature in ${ }^{\circ} \mathrm{C}$ (Yousef, 1985).

\section{Feeding frequency}

The treatments were applied to entire pen with primiparous cows in conventional farm and one pen in AMS farm and consisted in two periods with two different feeding frequency distribution replicated in two different season. Each period lasted two week: one week for adaptation and one for trial.

The feeding frequency was two $(7.00 \mathrm{~h}$ and $17.00 \mathrm{~h})$ or three $(8.00 \mathrm{~h}$, $11.00 \mathrm{~h}$ and $17.00 \mathrm{~h}$ ) and season summer and autumn in the conventional dairy farm; in AMS dairy farm the feeding frequency was one $(9.00 \mathrm{~h})$ or two $(9.00 \mathrm{~h}$ and $18.00 \mathrm{~h})$ and season spring and summer. All cows in the AMS farm received a TMR at feed bunk and a different amount of concentrate at the AMS during milking depending on milk yield.

\section{Behavioural recording}

All behaviours of the cows were monitored in continuous by video recording system for all duration of the study. The video surveillance system consisted of four IR day/night weather-proof varifocal cameras with 42 infrared led for night vision (420SS-EC5, Vigital Technology Ltd., Sheung Wan, Hong Kong) and a recording personal computer based on Windows XP Professional. The cameras each had a protective aluminium housing (IP66) and a 4.0 to $9.0 \mathrm{~mm}$ varifocal lens. The four cameras were placed about $5 \mathrm{~m}$ above the pen floor to allow for the complete visualization of the pens. The cameras were connected to a four channel video capture DVR4200 card (Huper Laboratories Co., Ltd., Taipei, Taiwan) that was integrated into the PC and that converted the analogue signal to a digital signal for subsequent storage on a hard disk. Each camera was set to continuously record at $640 \times 480$ resolution and 1 frames/s.

The analysis of the video recording data consisted of the evaluation of the number of dairy cows engaged in different behavioural activities (i.e., feeding, lying, and standing). Standing was considered to be an upright posture (i.e., motionless or walking), while the lying category included only cows that were observed in total lateral or sternal recum-

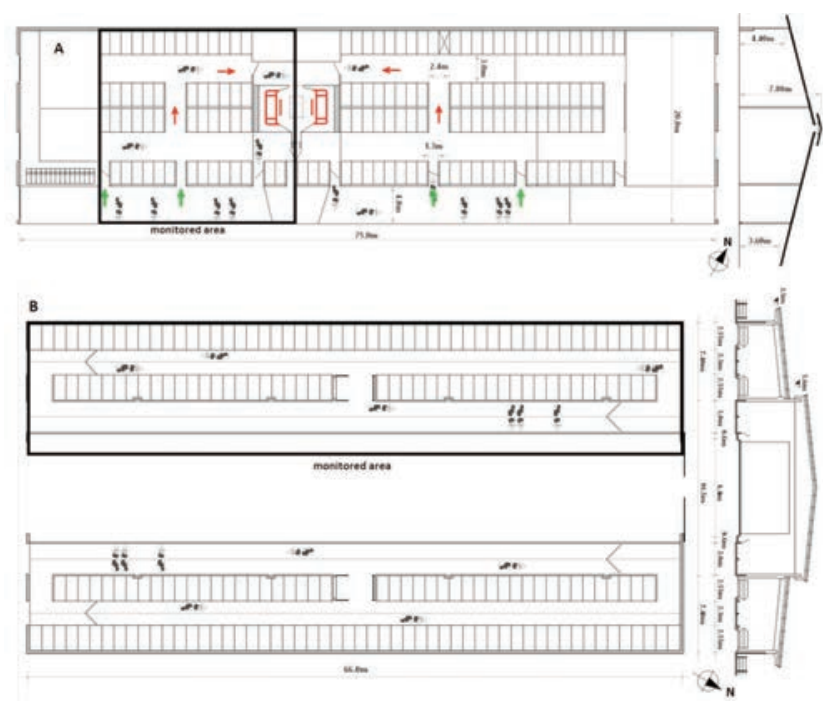

Figure 1. Layout of the monitored barn for the AMS farm (A) and the conventional farm (B). 
bency within the confines of a stall (Overton et al., 2002). Eating was defined as actively ingesting feed or water, or standing within $0.6 \mathrm{~m}$ of the feed bunk and oriented toward the feed (Overton et al., 2002). Behavioural activities were analysed at scan intervals of $60 \mathrm{~min}$ (Mattachini et al., 2011) for each barn to create 2 databases. For each database and for each hour, specific cow behavioural indices were calculated, namely CLI, SUI, CSI, SPI, and CFI. The cow lying index (CLI) describes the number of animal resting in the stall and is defined as total number lying in free stalls divided by the total number of cows in the barn. The free-stall use index proportion of eligible lying (SUI) was defined as total number of cows lying in free stalls divided by the total number of cows in the barn that were not eating during that time period (Overton et al., 2002). The cow standing index (CSI) was calculated as the number of cows observed standing (not lying and eating), divided by the total number of cows in the barn. The stall perching index (SPI) defined the proportion of cows touching a stall that were standing with only the front 2 feet in the stall and the rear feet in the alley (Cook et al., 2005). The cow feeding index (CFI) was obtained counting the cows at the feed bunk (Wagner-Storch and Palmer, 2003). The entire behavioural observation period covered $8 \mathrm{~d}$ for each treatment in each period for a total of $32 \mathrm{~d}$ for each farm.

Table 1. Climatic and feeding frequency effects on behaviour indices

\begin{tabular}{|c|c|c|c|c|c|c|c|}
\hline farm & Factor & CL & CSI & SUI & SPI & CFI & AMS \\
\hline \multirow[t]{4}{*}{ AMS farm } & Weather & $* *$ & $* *$ & $* *$ & $* *$ & $*$ & $*$ \\
\hline & Feeding frequency & $* *$ & n.s. & n.s. & n.s. & $*$ & $* *$ \\
\hline & Hour & $* *$ & $* *$ & $* *$ & $* *$ & $* *$ & $* *$ \\
\hline & Environmental condition x Feeding Frequency & $*$ & n.s. & $*$ & n.s. & n.s. & $*$ \\
\hline \multirow[t]{4}{*}{ Conventional farm } & Weather & $* *$ & $* *$ & ** & $* *$ & n.s. & - \\
\hline & Feeding frequency & n.s. & $*$ & n.s & n.s. & n.s. & - \\
\hline & Hour & $* *$ & $* *$ & $* *$ & $* *$ & $* *$ & - \\
\hline & Environmental condition x Feeding Frequency & n.s. & $* *$ & n.s. & $* *$ & n.s. & - \\
\hline
\end{tabular}

** $\mathrm{P} \leq 0.01 ;{ }^{*} \mathrm{P} \leq 0.05 ;$ n.s. not significant

Table 2. Mean values of the indices and THI for the two frequencies of feed delivery (1× vs 2$)$ and for the two periods (hot and cool) for the automatic milking system farm.

\begin{tabular}{|c|c|c|c|c|c|c|c|c|}
\hline & & & Num & of feeding & on per & W & & \\
\hline & & & & & & & & \\
\hline & Mean & $\begin{array}{l}\text { Standard } \\
\text { deviation }\end{array}$ & Mean & $\begin{array}{l}\text { Standard } \\
\text { deviation }\end{array}$ & Mean & $\begin{array}{l}\text { Standard } \\
\text { deviation }\end{array}$ & Mean & $\begin{array}{l}\text { Standard } \\
\text { deviation }\end{array}$ \\
\hline CLI & 0.47 & 0.13 & 0.54 & 0.12 & 0.46 & 0.14 & 0.50 & 0.14 \\
\hline CSI & 0.28 & 0.10 & 0.22 & 0.08 & 0.26 & 0.09 & 0.22 & 0.08 \\
\hline SUI & 0.62 & 0.14 & 0.70 & 0.12 & 0.63 & 0.12 & 0.69 & 0.12 \\
\hline SPI & 0.14 & 0.06 & 0.11 & 0.06 & 0.14 & 0.06 & 0.11 & 0.05 \\
\hline $\mathrm{CFI}$ & 0.17 & 0.09 & 0.18 & 0.09 & 0.18 & 0.11 & 0.19 & 0.09 \\
\hline AMS & 0.08 & 0.08 & 0.06 & 0.05 & 0.09 & 0.07 & 0.09 & 0.07 \\
\hline THI & 72.91 & 3.88 & 60.32 & 3.09 & 71.36 & 3.63 & 66.43 & 3.47 \\
\hline
\end{tabular}

Table 3. Mean values of the indices and THI for the two frequencies of feed delivery $(2 \times$ vs $3 \times)$ and for the two periods (hot and cool) for the conventional farm.

\begin{tabular}{|c|c|c|c|c|c|c|c|c|}
\hline & \multicolumn{4}{|c|}{$\begin{array}{c}2 \\
\text { Weather }\end{array}$} & \multicolumn{4}{|c|}{$\begin{array}{c}3 \\
\text { Weather }\end{array}$} \\
\hline & \multicolumn{2}{|c|}{ hot } & \multicolumn{2}{|c|}{ cool } & \multicolumn{2}{|c|}{ hot } & \multicolumn{2}{|c|}{ cool } \\
\hline & Mean & $\begin{array}{l}\text { Standard } \\
\text { deviation }\end{array}$ & Mean & $\begin{array}{l}\text { Standard } \\
\text { deviation }\end{array}$ & Mean & $\begin{array}{l}\text { Standard } \\
\text { deviation }\end{array}$ & Mean & $\begin{array}{l}\text { Standard } \\
\text { deviation }\end{array}$ \\
\hline CLI & 0.54 & 0.20 & 0.62 & 0.21 & 0.52 & 0.17 & 0.61 & 0.19 \\
\hline CSI & 0.21 & 0.09 & 0.14 & 0.07 & 0.23 & 0.09 & 0.14 & 0.06 \\
\hline SUI & 0.71 & 0.15 & 0.79 & 0.15 & 0.68 & 0.14 & 0.79 & 0.16 \\
\hline SPI & 0.08 & 0.04 & 0.06 & 0.04 & 0.09 & 0.04 & 0.05 & 0.03 \\
\hline $\mathrm{CFI}$ & 0.25 & 0.18 & 0.24 & 0.20 & 0.25 & 0.13 & 0.25 & 0.18 \\
\hline THI & 71.93 & 3.50 & 58.40 & 2.91 & 74.31 & 3.12 & 56.96 & 3.13 \\
\hline
\end{tabular}




\section{Statistical analysis}

Behavioural indices were not normally distributed as defined by the Kolmogorov-Smirnov test and these indices were then square root-arcsine transformed to achieve normal distribution (Mitlohner et al., 2001). For the analysis of behaviours (CLI, CSI, SUI, SPI, CFI, AMS), both farms were considered as the experimental unit, with measures from multiple days and cows averaged to create one observation per hour of the day, per farm, per treatment ( 1 vs. $2 ; 2$ vs. 3 ) and per environmental condition (cool and hot). Effect of the hour of the day was considered in both farms. In conventional farm milking hours were excluded. An ANOVA was carried out considering as factors: feeding frequency, environmental condition, hour and interaction feeding frequency $\mathrm{x}$ environmental condition.

DMI, milk yield, and THI were tested by ANOVA using the same factorial model for daily values.

In statistical analysis, significance was declared when $P<0.05\left(^{*} P\right.$ $\left.<0.05 ;{ }^{* *} P<0.01 ;{ }^{* * *} P<0.001\right)$.

\section{Results}

As expected, almost all behavioral indices have been significantly affected by environmental conditions both in conventional and AMS farm (Table 1).

Although the THI values were not particularly high also in the hot period $(<73)$ the differences in the behavioral activity in comparison to the cool period were marked (table 2): CLI decreased of $10-15 \%$ while cows were standing longer (23-50\%). Thus also the SUI decreased in hot conditions. The SPI shows an significant increment in both farms $(>30 \%)$ revealing cows were less comfortable. CFI has been affected in a very limited way in the conventional farm and the differences are not significant while slightly decreased in the AMS farm ($5 \%)$.

The increase in the feeding frequency has caused different effect in the two farms.

In AMS farm significantly affected CLI, CFI and AMS (Table1). As expected, CLI was reduced when the number of the feeding distribution per day increased, but the effect is significantly higher (interaction significance $\mathrm{P}<0.05$ ) in the cool period. In hot period the variation of this index is very limited. The consequence is a higher CFI that resulted $8 \%$ higher in both periods. As the traffic is forced through the milking, also a significant increase of the time spent in this area has been recorded. Thus the effect in the AMS farm of the increase of the number of feeding distribution per day has been to reduce the time spent lying and an increase of the time spent trying to reach the manger and in feeding.

The effect in the conventional farm confirms a tendency of reduction of the CLI (not significant) and an increase of time spent standing mainly in the hot period, confirmed by a significant interaction (Table 1). In this farm the increase of the number of distribution per day seems to have induced cows to rise and to stand. Although they did not spend a significant longer time at the manger, the tendency also in this case was to increase the time spend feeding (Table 3).

Figure 2 reports the average hourly behavior of cows in the experimental periods. The indices were of course significantly affected by the time of the day. It can be noticed that the conventional farm cows is to rest just after the morning milking but, when the feed is distributed a great number of cows reach the manger. After the afternoon milking

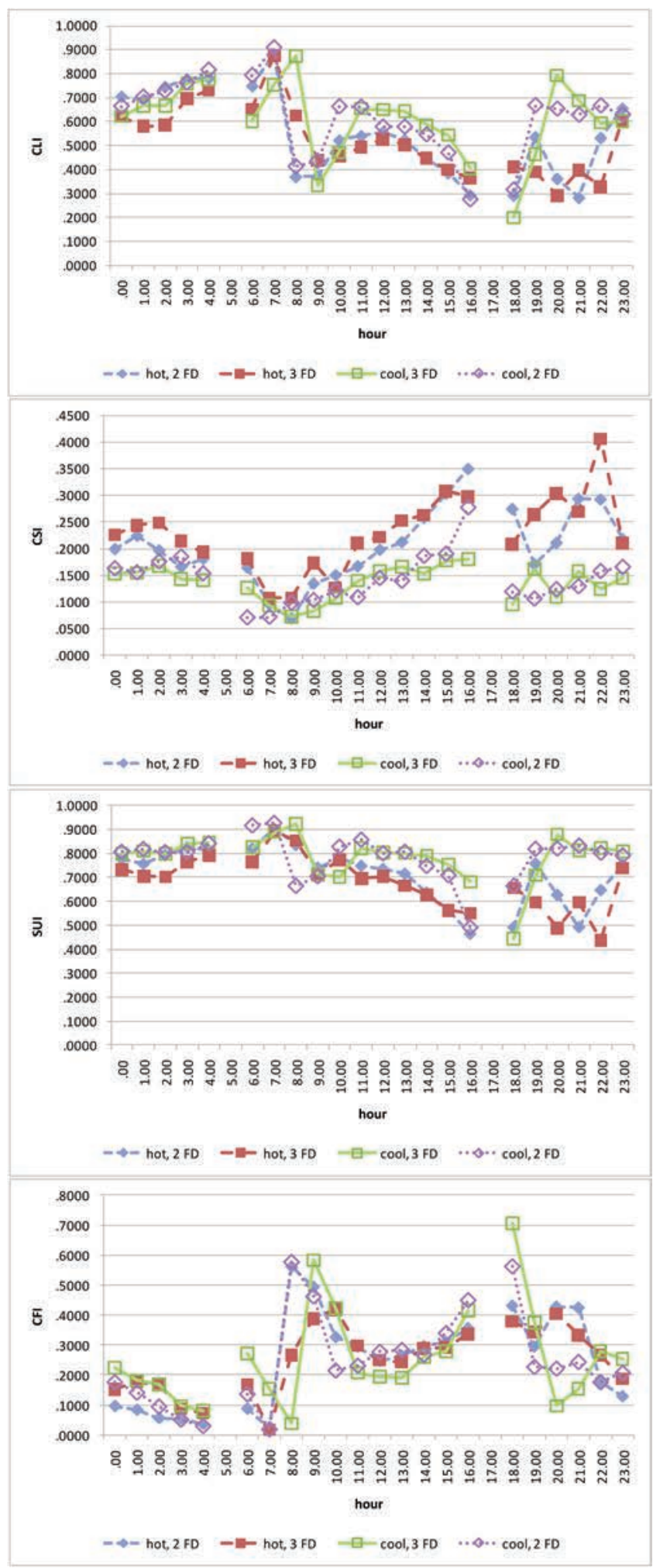

Figure 2. Hourly means of the behavioural indices for the two farms in the four test conditions: two weather (hot and cool) and two feed delivery frequencies ( 2 and 3 times a day for the conventional farm; 1 to 2 times a day for the AMS farm). 
cows go directly to the manger as feed is already available. In AMS farm the feeding activity is reduced from 10 p.m. to 8 a.m. and then remain quite high (more than $20 \%$ of cows) during the day. The effect of the number of feeding distribution during the day is not evident in both farms. This is probably due to the operation of pushing feed in the manger that is carried out by both farms periodically during the day.

The effect of the number of distribution of feed per day results clearly also by the comparison of the daily time budget of the two test conditions for the two farms (Figure 3).

The variations are similar in both farms. When the number of distributions rise, the feeding time increase while the lying and standing time decrease. From figure 3 it can also be noticed that in both farms the daily time a cow spend for lying and feeding seems to be constant as well as the time spent standing and milking. In AMS farm cows significantly increase the time spent in the AMS holding area, while in conventional farm they increase the standing time. In any case, the variation of the feeding distribution affected negatively the daily time budget.

\section{Conclusions}

The most significant effect on cow behavioural activity is however related to THI also when daily values are in the range where heat stress should not occur.

The variation in the frequency of feed delivery seems to affect the cow behavioural activity but only in a limited way and to modify only slightly the daily averages of the time spent in different activities. The increase of the standing time for the conventional far and time spend in the holding area for the AMS farm is the main effect recorded in this experiment.

Further investigations are required to evaluate other aspects like the number of bouts and the duration of each lying period. Of course, in farms where the feeding operations are not automatized, the farmer should evaluate carefully if the higher cost of an extra feeding delivery is compensated by the increase in milk production.

The adverse effect of a more frequent feed distribution on cow daily time budget should therefore be carefully considered. Although it

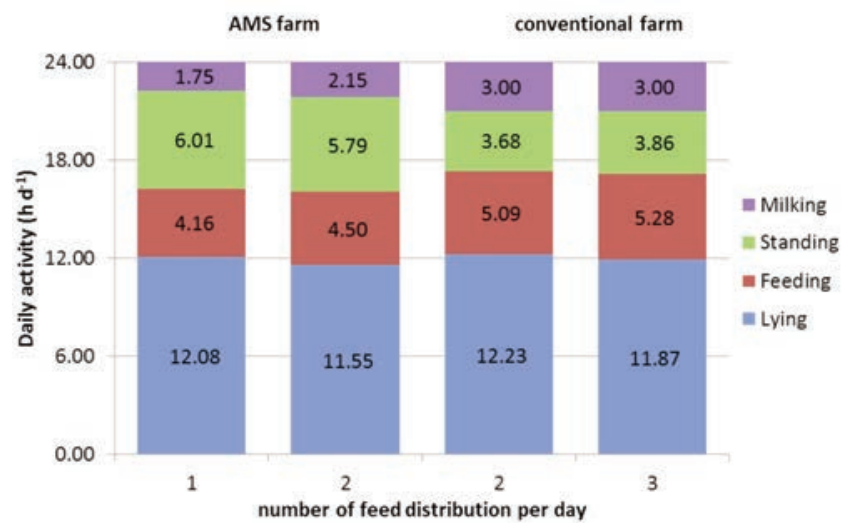

Figure 3. Comparison of the Daily Time Budget for the two farms considered in relation to the number of feed distributions per day. seems to have limited effect, the longer standing time cannot be ignored especially in farm equipped with AMS where the cow traffic system might worsen the consequences of a more frequent feed delivery.

\section{References}

Cook N. B., Mentink R.L., Bennet T.B., Burgi K. 2007. The effect of heat stress and lameness on time budgets of lactating cows. J. Dairy Sci. 90:1674-1682.

DeVries T.J., von Keyserlingk M.A.G., Weary D.M., Beauchemin K.A. 2003. Measuring the feeding behavior of lactating dairy cows in early to peak lactation. J. Dairy Sci. 86:3354-3361.

DeVries T.J., von Keyserlingk M.A.G. 2005. Time of feed delivery affects the feeding and lying patterns of dairy cows. J. Dairy Sci. 88:625631

DeVries T.J., von Keyserlingk M.A.G., Beauchemin K.A., 2005. Frequency of feed delivery affects the behavior of lactating dairy cows. J. Dairy Sci. 88:3553-3562

Gibson J. P. 1984. The effects of frequency of feeding on milk production of dairy cattle: An analysis of published results. Anim. Prod. $38: 181-189$.

Grant R. J., Albright J. L. 2001. Effect of animal grouping on feeding behavior and intake of dairy cattle. J. Dairy Sci. 84:E156-163

Grant R. J., Albright J. L. 2000. Feeding behaviour. Page 365-382 in Farm Animal Metabolism and Nutrition. J.P.F. D'Mello, ed. CABI Publishing,Wallingford, Oxon, UK

Kudrna V., Lang P., Mlazovska P., 2001. Frequency of feeding with TMR in dairy cows in summer season. Czech J. Anim. Sci. 46:313-319.

Haley D. B., Rushen J., de Passillé A. M. 2000. Behavioural indicators of cow comfort: activity and resting behaviour of dairy cows in two types of housing. Can. Vet. J. 80.2:257 -263

Halachmi I., Metz J. H. M., Maltz E., Dijkhuizen A. A., Speelman L. 2000. Designing the optimal robotic barn. Part 1: Quantifying facility usage, J. Agric. Eng. Res. 76:37-49.

Hermans G. G. N., Ipema A. H., Stefanowska J., Metz J. H. M. 2003. The effect of two traffic situations on the behavior and performance of cows in an automatic milking system. J. Dairy Sci. 86:1997-2004.

Le Liboux S., Peyraud J.L., 1999. Effect of forage particle size and feeding frequency on fermentation patterns and sites and extent of digestion in dairy cows fed mixed diets. Anim. Feed Sci. Tech. $76: 297-319$.

Mäntysaari P., Khalili H., Sariola J., 2006. Effect of feeding frequency of a total mixed ration on the performance of high-yielding dairy cows. J. Dairy Sci. 89:4312-4320.

Mattachini G., Riva E., Provolo G. 2011. The lying and standing activity indices of dairy cows in free-stall housing. Appl. Anim. Behav. Sci. 129:18-27.

Melin M., Wiktorsson H., Norell L. 2005. Analysis of feeding and drinking patterns of dairy cows in two cow traffic situations in automatic milking systems. J. Dairy Sci. 88:71-85.

Mitlohner F.M., Morrow-Tesch J.L., Wilson S.C., Dailey J.W., McGlone J.J. 2001. Behavioral sampling techniques for feedlot cattle. J. Dairy Sci. 79:1189-1193.

Overton M.W., Sischo W.M. Temple G.D. Moore D.A. 2002. Using timelapse video photography to assess dairy cattle lying behavior in a free-stall barn. J. Dairy Sci. 85:2407-2413.

Oostra H.H., Stefanowska J., Sallvik K., 2005. The effects of feeding frequency on waiting time, milking frequency, cubicle and feeding fence utilization for cows in an automatic milking system. Acta Agr. Scand. A-An. 55.4:158 - 165.

Phillips C.J.C., Rind M.I. 2001. The effects of frequency of feeding a 
total mixed ration on the production and behavior of dairy cows. J. Dairy Sci. 84:1979-1987.

Prescott N.B. Mottram, T.T., Webster A.J.F. 1998. Relative motivations of dairy cows to be milked or fed in a Y-maze and an automatic milking system. Appl. Anim. Behav. Sci. 57:23-33.

Shabi Z., Bruckental I., Zamwell S., Tagari H., Arieli A. 1999. Effects of extrusion of grain and feeding frequency on rumen fermentation, nutrient digestibility, and milk yield and composition in dairy cows. J. Dairy Sci. 82:1252-1260.

Tanida H., Swanson L.V., Hohenboken W.D. 1984. Effect of artificial photoperiod on eating behavior and other behavioral observations of dairy cows. J. Dairy Sci. 67.3:585-591

Wagner-Storch A.M., Palmer R.W. 2003. Feeding behavior, milking behavior, and milk yields of cows milked in a parlor versus an automatic milking system. J. Dairy Sci. 86:1494-1502

West J. W., 2003. Effects of heat-stress on production in dairy cattle J. Dairy Sci. 86:2131-2144.

Wes, J.W., Mullini, B.G., Bernar, J.K., 2003. Effects of hot, humid weather on milk temperature, dry matter intake, and milk yield of lactating dairy cows. J. Dairy Sci.86: 232-242. 